\title{
Computerized Assessment of Memory Performance in Dementia
}

\author{
FRANCISCO I. PEREZ, NANCY A. HRUSKA, REBECCA L. STELL AND VICTOR M. RIVERA
}

\begin{abstract}
SUMMARY: Memory deficits in demented patients were studied by applying a computerized system to titrate individual memory performance. Two delayed matching to sample tasks were used. $A B A 1$ involved random visual shapes used as a measure of visual memory. ABA 2 involved nonsense syllable trigrams used as a measure of verbal memory. A Human Test System panel with a display screen was utilized. This screen was a rear view projection window divided into four independent $3 \times 2$ sections arranged in a $2 \times 2$ matrix. The sample stimulus appeared on the upper left window for one second. The delay inter-
\end{abstract}

RESUME: Nous avons étudié les déficits mnésiques chez des patients déments en nous servant d'un système par ordinateur afin de calibrer la performance mnésique individuelle. Nous avons utilisé deux tâches types: $A B A 1$ implique des formes visuelles au hasard comme mesure de la mémoire visuelle. ABA2 implique des trigrammes de syllabes nonsens comme mesure de la mémoire verbale. Un paneau "Human Test System" avec écran témoin fut utilisé. Cet écran est une fenêtre de rétroprojection divisée en 4 sections indépendantes $(3 \times 2)$ organisées en une matrice de $2 \times 2$. Le stimulus témoin apparaît pour une seconde val between stimulus sample and choices varied by 7 seconds dependent upon patient performance per trial. Also utilized was a color distractor task. Task parameters, data acquisition, retrieval, and graphic print-outs were all computerized. Individual titration levels reflected the severity of neurological impairment. Computerized assessment enabled subtle changes in memory performance to be readily identified. Implications for use of the system as a screening device in the assessment of mental changes in the elderly are apparent.

dans la fenêtre gauche supérieure. L'intervale de délai entre le stimulus et le choix variait de 7 secondes selon la performance des patients dans un même essai. Nous avons également utilisé une tâche distrayante de couleur. Les paramètres de tâche, l'acquisition des données, leur reprise et les imprimés graphiques sont tous faits par ordinateur. L'évaluation par ordinateur permet l'identification facile des changements subtils dans la performance mnésique. L'utilité de ce système dans l'évaluation des fonctions mentales des personnes âgées est évidente.
From the Neuropsychology Laboratory, Departments of Neurology and Psychiatry, The Neurosensory Center of Houston, Baylor College of Medicine, Houston, Texas.

This work was supported by Grants NS-09287-07 and NS-13708-01 from the National Institute of Neurological and Communicative Disorders and Stroke, National Institutes of Health, Bethesda, Maryland, 20017.

Reprint Requests to: Francisco 1. Perez, Ph.D. Neuropsychology Laboratory, Department of Neurology, Baylor College of Medicine, Houston, Texas 77030. U.S.A.

\section{INTRODUCTION}

Disorders of memory are a characteristic and often prominent feature of dementia and may be one of the first indications that adverse changes in the mental processes are taking place (Perez et al, 1975). Karp (1974) considers memory loss as a logical focal point for the clinical analysis of disorders of mental functioning in the dementias. Attempts have been made to elucidate the nature of the memory deficit in the dementias associated with neuronal atrophy in the pre-senile age group by Miller (1971, 1972) and Pearce and Miller (1973) and in the senile age group by Inglis (1970). Perez et al (1975) examined the memory performance of three distinct groups of patients with dementia secondary to Alzheimer's disease multiple infarctions and vertebrobasilar insufficiency using the Wechsler Memory Scale. They found that the Alzheimer's group had a significantly more severe memory disorder than the two cerebrovascular disease groups.

The analysis of the memory deficits in dementia have relied primarily on clinical psychological test procedures. However, some uncontrolled variables may lie outside the boundaries of immediate measurement and control in the clinical setting and cannot be identified and measured properly with current neuropsychological memory assessment procedures. These psychological testing procedures are usually gross and indirect and are not sensitive to small behavioral changes. Correlations of brain lesions and behavioral deficits are exercises in futility if either set of observations is improperly controlled. The behavioral assessment must be as 
rigorous as the anatomic if the correlation is to be meaningful (Sidman et al, 1971).

Much progress has recently been made in a wide range of areas in psychology by the systematic application of the precise methodology of the experimental analysis of behavior. This approach emphasizes the technical basis of psychology and proposes that the extent to which behavioral phenomena can be studied at any time is limited by the current state of behavioral technology. Characteristics of the behavioral analysis methodology include: a) the intensive study of individual subjects; b) control of the assessment environment; c) continuous observation and recording of behavior, and d) automatic recording and programming (Honig, 1966). The purpose of the present study is to apply this behavioral methodology using a computerized system in order to titrate short-term recognition memory in patients with dementia secondary to neurological disorders.

\section{METHODS}

\section{Diagnostic Criteria}

The diagnosis for each patient was determined after an extensive neurological and clinical work-up was completed, including a neurological examination, electroencephalography, brain scan, and in selective patients, angiograms and computerized axial tomography. A brief clinical description of each patient will accompany the presentation of his data. In addition, the performance of a normal control elderly individual will be presented.

\section{Apparatus and Procedure}

The present study applied an adjusting delayed matching to sample (DMTS) procedure in order to individually titrate short-term recognition memory in elderly patients with neurological disorders. The DMTS procedure has been used by D'Amato (1973) to study short term memory in monkeys. Shimp and Moffitt (1974) have studied short term memory in the pigeon using DMTS procedures. Sidman et al. (1971) have applied the DMTS procedure in order to study the relationship of language disorders and memory deficits in aphasic patients.
Each subject sat in a dark room in front of a Human Test System panel with a display screen. This screen was a rear view projection window divided into four independent $3 \times 2$ inch sections arranged in a $2 \times 2$ inch matrix. The sample stimulus appeared on the upper left window for one second. Three choices appeared on the other windows after a delayed interval. On trial one, the choice stimuli were presented immediately after the sample stimulus. On successive trials, the delayed adjusting interval increased or decreased by seven seconds depending upon the performance of the patient on a given trial. A pleasant feedback tone was presented with each correct response. An adjacent simultaneous color matching to sample task was used as a distractor (interference) during the delay interval. The programming of the stimuli and responses as well as data acquisition was automated using a solid-state digit-bits programming system. Data storage, analysis and retrieval was performed on a PDP11/35 computer.

\section{Stimulus Material}

Two tasks were developed using verbal and non-verbal stimulus material. Each patient performed on each task.

ABA l: Consisted of random shapes generated by Vanderplas and Garvin (1959). They developed 180 designs with six levels of complexity. Complexity refers to the number of corners: four, six, eight, sixteen, and twentyfour. The thirty sample stimuli for ABA 1 consisted of shapes with sixteen and twenty-four corners. Choice stimuli were drawn from the same level of complexity as the sample.

ABA2: Consisted of nonsense syllable trigrams taken from norms prepared by Witmer (1935). The thirty sample stimuli for ABA2 consisted of trigrams with low association values of 25 to 29 percent. The three choice stimuli for each trial were drawn from the same low association value and with an identical first consonant as the sample stimulus.

\section{RESULTS}

Figures 1-10 show the actual computer print-out of the performance for each individual on ABAl (Visual shapes recognition task) and $\mathrm{ABA} 2$
(Nonsense syllable trigram recognition task). Each test consisted of 5 practice trials in order to shape the performance of the subject. The actual test consisted of 30 trials except in specific cases noted where the test was discontinued because of the necessary information having been obtained. On each figure a "+" indicates correct recognition and a "." indicates incorrect recognition on a given trial. The specific delay interval for a given trial is also presented. Summary statistics are presented at the bottom of each figure indicating the total percentage of correct and incorrect discriminations as well as the greatest delay interval for a correct or incorrect discrimination. Each patient is coded by a number and is discussed separately.

Control \#756 is a 62 year old, righthanded male with a high school education. His Wechsler Adult Intelligence Scale (WAIS) scores were: Full IQ 110; Verbal IQ 109; Performance IQ 112. His Wechsler Memory Scale Quotient (MQ) was 106. This individual is currently employed in a technical position and has no risk factors for cerebrovascular disease nor any other known neurological disorder. Figures 1 and 2 show that he obtained a $93 \%$ accuracy on ABA 1 with a delay interval of 156.9 seconds on trial 30. On ABA2, his accuracy was $80 \%$ with a ceiling delay interval of 108 seconds. His performance is compatible with our series of normal controls, with no neurological dysfunction.

Patient \#983 is a 62 year old, righthanded male who is a retired physician. Medical records indicate that over the past three years he has had 12 attacks of transient global amnesia lasting a few minutes to as long as half an hour, with decreased recent memory, drop attacks, and intermittent numbness. The EEG studies showed some generalized low voltage fast activity in the anterior leads but essentially within the range of normal variation. The patient underwent a right carotid endarterectomy in 1973. The neuropsychological results showed a Full WAIS IQ of 110; Verbal IQ 104, and Performance IQ 117. His MQ was 105 . The patient carries the diagnosis of transient ischemic attacks secondary to vertebrobasilar insufficiency associated with right vertebral stenosis as well as postoperative status right carotid endarterectomy.

Figures 3 and 4 show his performance. Comparison of his performance on $\mathrm{ABA} 1$ and $A B A 2$ show a significant discrepancy. This patient only obtained $60 \%$ accuracy 
NEUROPSYCHOLOGY LABORATORY - BAYLOR COLLEGE OF MEDICINE

I75O!
RIGHTHANDED MALE O2 YRS*
DIAGNOSISI NORMAL

TEST I IABAI

DELAY INTERVAL

Practice Trials

$\begin{array}{lll}1 \\ 2 \\ 3 \\ 4\end{array} \div \cdots+\cdots+\cdots$

1.00

$\begin{array}{rr}7.90 & 2 \\ 14.20 & 3 \\ 11.00 & 4 \\ 7.90 & 5\end{array}$

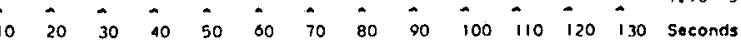
Test Trials

$\frac{1}{2}+\cdots$

35

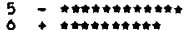

8
8

10

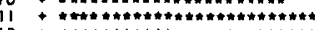

120

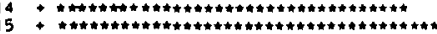

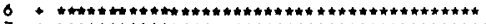

18

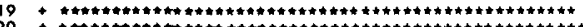

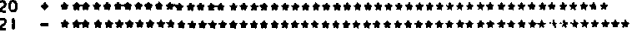

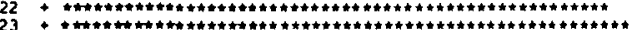

(l)

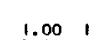

$\begin{array}{ll}1.00 & 1 \\ 7.90 & 2 \\ 4.10 & 3\end{array}$

14.10
20.20
20.40

20.40
20.20

0.507
32.708

4.80110

51.00
56.70

$\begin{array}{lll}53.40 & 13 \\ 60.80 & 14 \\ 75.70 & 15\end{array}$

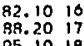

95.1018

107.00
113.20
117

113.2021

117.0022
113.502 .3

25
20

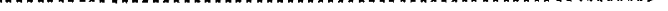

28
29
30

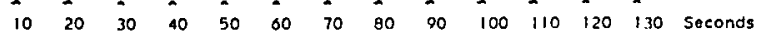

TEST TRIALS MEAN $S D$ GREATEST

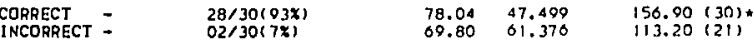

Figure I - Random Shape Discrimination Performance for Control \#756.

NEUROPSYCHOLOCY LABORATORY - BAYLOR COLLEGE OF MEDICINE

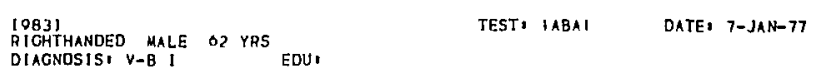

DELAY INTERVAL

Practice Trials

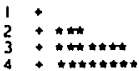

$\begin{array}{rr}.00 & 1 \\ 7.80 & 2 \\ 14.00 & 3 \\ 20.10 & 4\end{array}$

$4:$

26.405

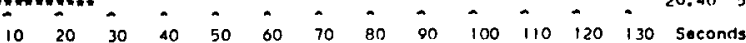
Tost Trials

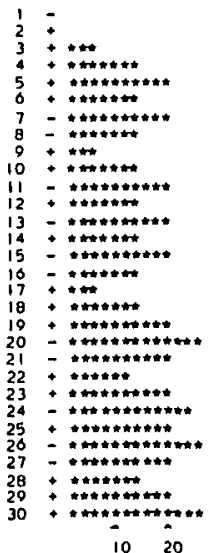

$\begin{array}{ll}1.00 & 1 \\ 1.00 & 2 \\ 7.80 & 3\end{array}$

$\begin{array}{rr}4.10 & 4 \\ 20.30 & 5 \\ 1.10 & 0\end{array}$

20.107

7.900

4.10
20.20

4.1014

4.0010

$\begin{array}{rl}7.90 & 17 \\ 18.00 & 18\end{array}$

20.10
26.40
20

13.9022
20.2023

25.8024

20.2020

20.0028

$10 \quad 20 \quad 30$ io 50 bo 70 bo 00 io 100 i10 120 i 30 seconds TEST TRIALS MEAN SD GREATEST

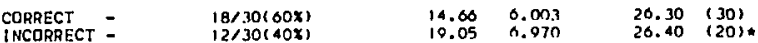

Figure 3 - Random Shape Discrimination Performance for Patient \#983.
NEUROPSYCHOLOCY LABORATORY - BAYLOR COLLEGE OF MEDICINE

[750]
BIGTHANDED MALE O2 YRS*
DIAGNDSIS! NORMAL

TEST, IABA2

OATE, 19-MOV-70

DELAY INTERVAL

Practice Trials

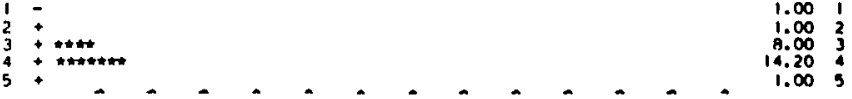

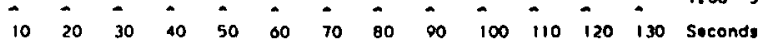
Test Trials

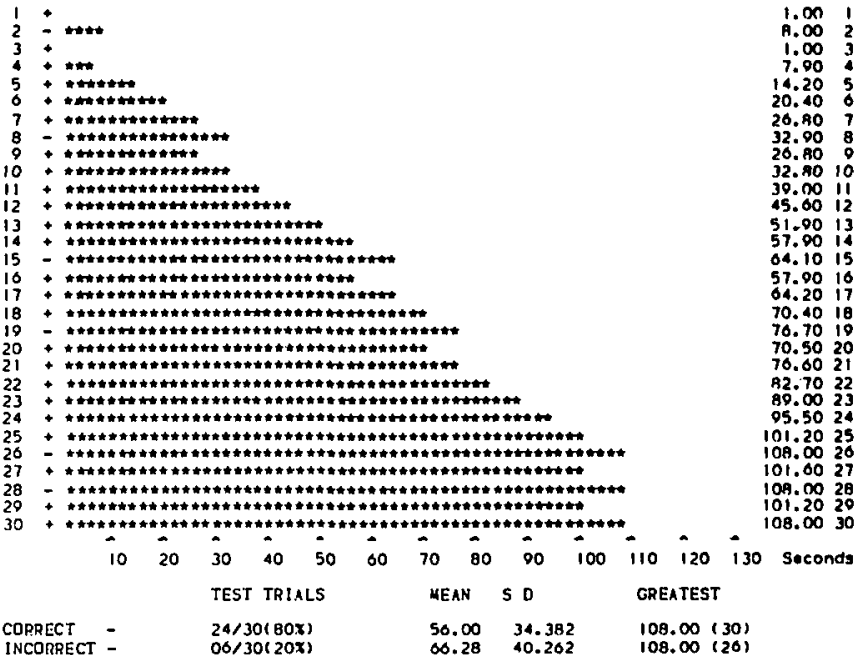

Figure 2 - Nonsense Syllable Trigram Discrimination Performance for Control \#756.

NEUROPSYCHOLOGY LABORATORY - BAYLOR COLLEGE OF MFDICINF

I983I
RIGHAMADED MALE OZ YRS EDV.
DIAGNOSIS: $V-B$ I

TEST I IABA2

DATE, 7-JANG 77

DELAY INTERYAL

Proctice Trials

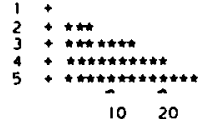

1.00
7.80
1.00
0.10

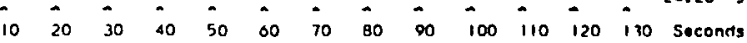
Test Trials

$\frac{1}{3} \div$

$\int_{0}^{2}+2$

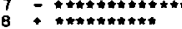

10

11 A HAm

13

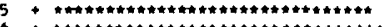

7 :

(

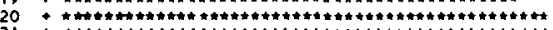

223

25

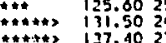

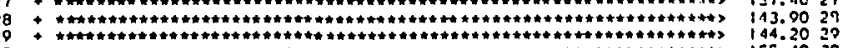

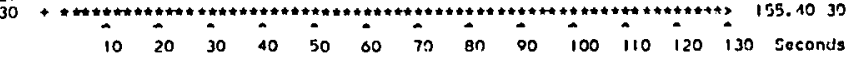

TEST TRIALS MEAN 50 CREATEST

$\begin{array}{lllll}\text { CORAECT }- & 28 / 30(93 \times) & 73.70 & 48.681 & 155.40(33) * \\ \text { [NCORRECT } & 02 / 30(7 \times) & 17.05 & 13.081 & 20.30(7)\end{array}$

Figure 4 - Nonsense Syllable Trigram Discrimination Performance for Patient \#983. 
on ABAl with a titration level of 26.40 seconds delayed interval. His ABA2 performance is basically normal with $93 \%$ accuracy and a titration level of 155.40 seconds delayed interval. Previous findings by Kimura (1963) have shown that visual recognition of nonsense figures is impaired after right hemisphere lesions. The results on the present patient with known right hemisphere cerebrovascular involvement of the carotid and vertebral arteries with poor performance on the visual recognition task corroborate these findings. It appears that ABAl is particularly sensitive to the titration of visual recognition memory.

Patient \#821 is a 69 year old, righthanded female with 14 years of education. Medical records indicate that the initial symptomatology started approximately six years ago with blurring of vision occasionally associated with dizziness, vertigo, staggering, and loss of consciousness. These attacks usually lasted about ten minutes. These symptoms were under control during the present examination. Repeated EEG records showed basically no change, with a moderately fast record but essentially within the range of normal variation. A left carotid and retrograde right brachial angiogram showed that the left carotid artery and the right vertebral and basilar arteries and their intracranial branches were unremarkable except for some increased arterial tortuosity and lumen margin irregularity. The intracranial branches of the right internal carotid artery were transiently and incompletely delineated, with both anterior cerebral arteries opacified during left internal carotid artery injection. The neuropsychological results showed a Full WAIS IQ of 134; Verbal IQ 141 and Performance IQ 122. Her MQ was 143. The patient carries the diagnosis of cerebrovascular insufficiency.

Figures 5 and 6 show her performance. The results show a significant discrepancy on her performance on $\mathrm{ABA} 1$ and $\mathrm{ABA} 2$. This patient obtained a $60 \%$ accuracy on ABAl with a titration level of 39.50 delayed interval. Her performance to trial 21 on $\mathrm{ABA} 2$ with $90 \%$ accuracy and a titration level of 102.5 seconds is basically normal. These results are similar to patient \#983 previously discussed. It is interesting to note that the neurological status and laboratory findings of these two patients are very similar. Direct replication of ABA1 and ABA2 on patients with similar neurological conditions provide additional support to the validity of the computerized memory assessment procedure.

Patient \#52 is a 59 year old right-handed male with 16 years education. $\mathrm{He}$ is a retired accountant. Medical records indicate that his problem started with memory difficulties first noted in 1969 which progressed and have become slowly worse since then. $\mathrm{He}$ is also described as becoming more irritable. No risk factors for cerebrovascular disease are present. Brain scans and brain flows revealed normal findings. The EEG showed marked diffuse slowing indicative of the presence of diffuse encephalopathy. Computerized axial tomography scanning through the posterior cranial fossa and cerebral hemispheres revealed moderate symmetrical enlargement of the bodies of the lateral ventricles and abnormally broad superficial cerebral sulci-changes which indicate the presence of bilateral cerebral atrophy. No indications of an intracranial mass lesion were recognized. The neuropsychological results showed a Full WAIS IQ of 103; Verbal IQ 106 and Performance IQ 91. His MQ was 86. The patient carries the diagnosis of Alzheimer's disease.

Figures 7 and 8 show the patient's performance. The results show a severe impairment of recognition memory on both tasks. On ABAl he obtained an accuracy of $53 \%$ with a maximum delayed interval level of 39.40 seconds on trial 27 . His ABA2 performance is profoundly impaired with $30 \%$ accuracy and a maximum
NEUROPSYCHOLOGY LABORATORY - BAYLOR COLLEGE OF MEDICINE

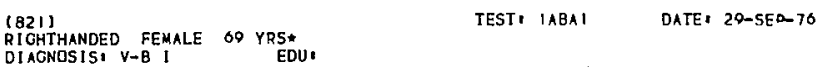

DELAY INTERVAL

Practice Trials
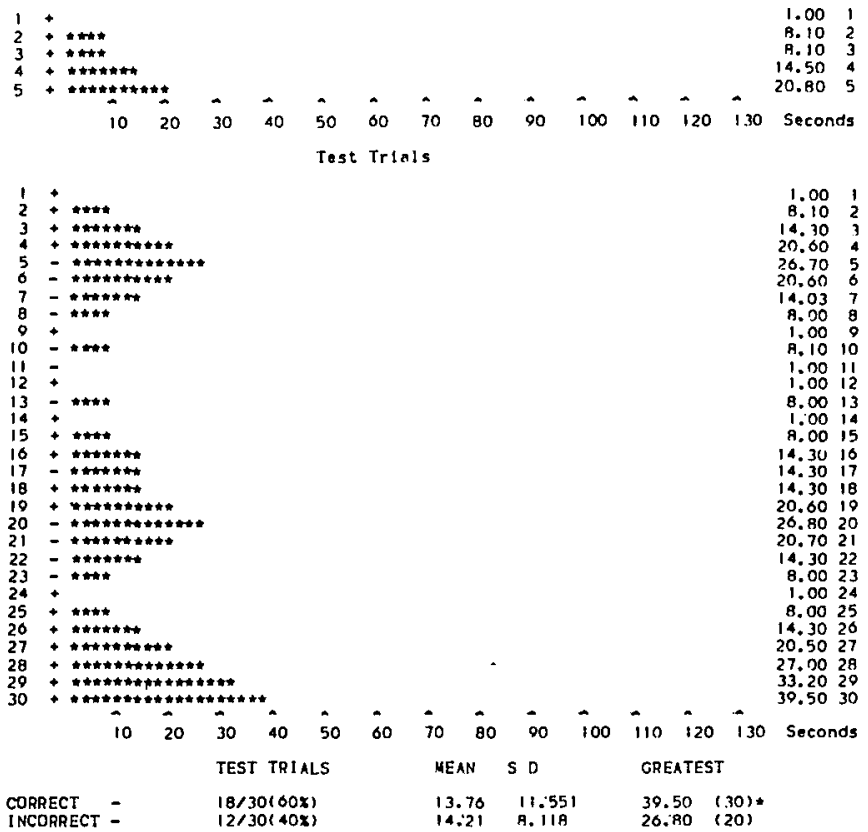

Figure 5 - Random Shape Discrimination Performance for Patient \#821.
NEUROPSYCHOLOGY LABORATORY - BAYLOR COLLEGE OF MEDICINE

$$
\begin{aligned}
& \text { [A2II) TEST: IABAZ DATE: 299-SEP-70 } \\
& \begin{array}{l}
\text { RIGHTHANDED FEMALE OQ YRS* } \\
\text { DIAGNOSISI } V-8 \text { I }
\end{array}
\end{aligned}
$$

DELAY INTERYAL.

Practice Trials

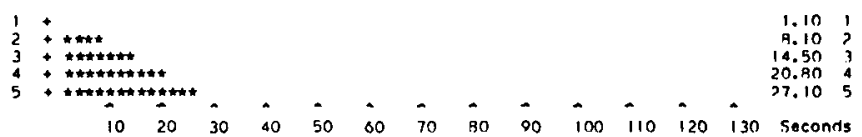

Test Trials

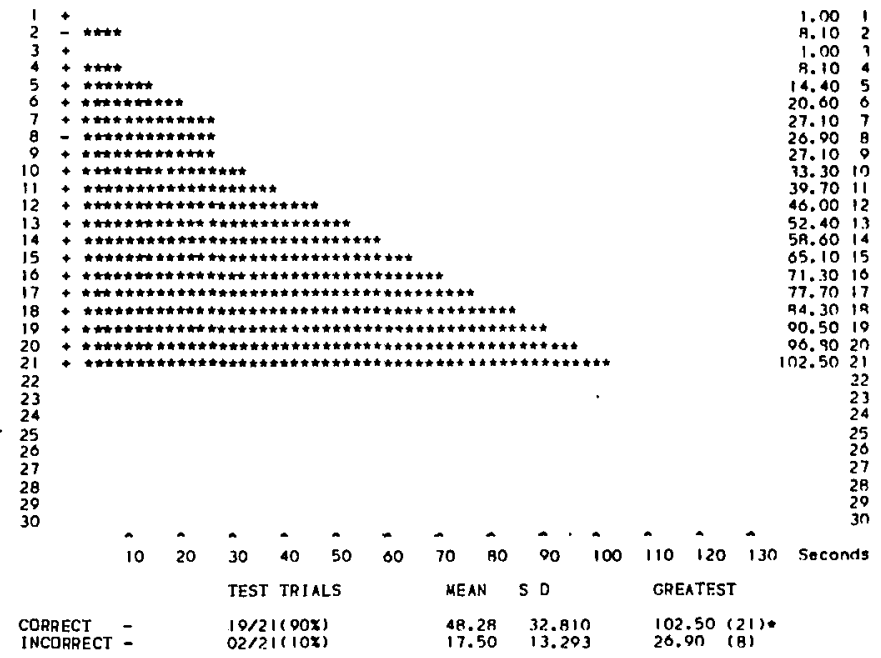

Figure 6 - Nonsense Syllable Trigram Discrimination Performance for Patient \#821. 
NEUROPSYOHOLOGY LABORATORY - BAYLOR COLLEGE OF MEDTCINE

I52)
RIGHTHANDED MALE 59 YRS
OI RGGNOSISI aLZ

TEST * ABA1

DELAY INTERYAL

Prectice Triols
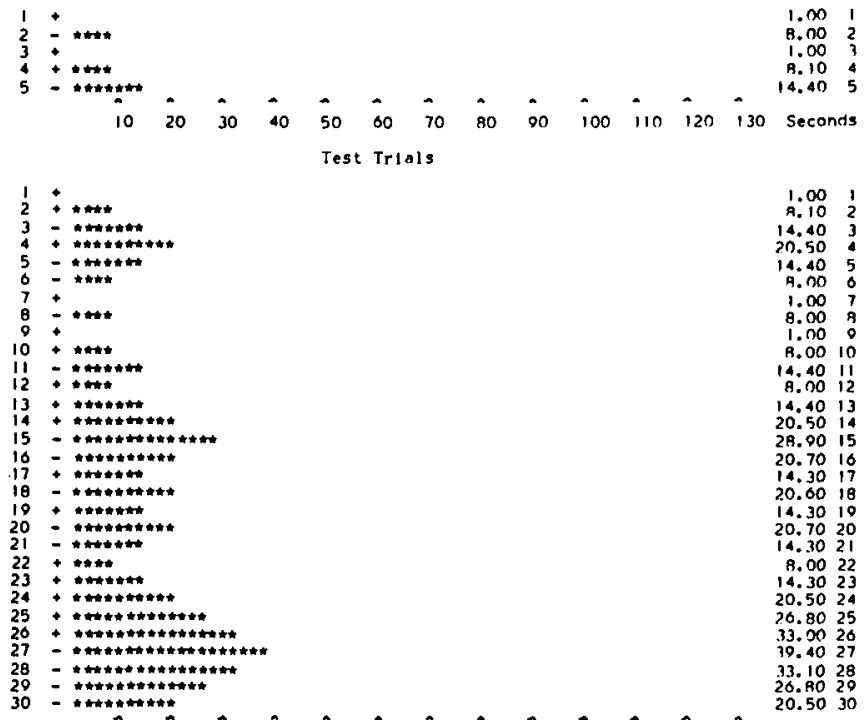

$\frac{1}{2}+\ldots+\cdots$

:

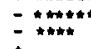

:

$+\ldots+\infty$

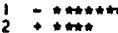

$13+$ :

15

10

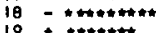

$20 \div 31$

22

$23+2010$

250

$27-27$

$28=28$

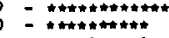

10 io

INCORRECT -

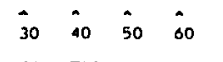

TEST TRIALS

$16 / 30(53 x)$
$14 / 30(47 x)$

$$
\text { io } 80 \text { कo } 100 \quad i
$$

MEAN $S$ D

$\begin{array}{ll}13.35 & 9.292 \\ 20.30 & 0.150\end{array}$

110 i2o

$\begin{array}{ll}33.0 n & (26) \\ 39.4 n & (27) *\end{array}$

Figure 7 - Random Shape Discrimination Performance for Patient \#52.

delayed interval level of 20.70 seconds on trial 27 . The computerized memory assessment results are compatible with the neurological status of the patient. They are indicative of a severe recognition memory dysfunction.

Patient \#23 is a 49 year old right-handed male with seven years of education. Medical records indicate a history of a right hemispheric stroke in 1974, with a prolonged left hemiparesis and left homonymous hemianopia. The patient has shown, since then, a general deterioration in mental function, with periods of confusion and forgetfulness and poor concentration. He has had three episodes of transient global amnesia. Angiography revealed generalized atherosclerotic small vessel disease. Risk factors for cerebrovascular disease are present, including hypertension and diabetes mellitus. The EEG was slightly slow but essentially within the range of normal variation. Computerized axial tomography revealed slight enlargment of the bodies of both lateral ventricles, right slightly greater than the left associated with some broad superficial cerebral hemispheric sulci bilaterally, attributed to the effects of cerebral atrophy. His neuropsychological results revealed a Full WAIS IQ of 74; Verb IQ 75, and Performance IQ 75. His MQ was 64.
NEUROPSYCHOLOGY LABORATORY - BAYLOR CULLFGE OF MFDICINI

$$
\begin{aligned}
& \text { 1521 } \\
& \text { RIGHTHANDED MALE } 59 \text { YRS EIU, } \\
& \text { DIAGNOSISE ALZ }
\end{aligned}
$$

DELAY IHIERVAL.

Practice Trinis

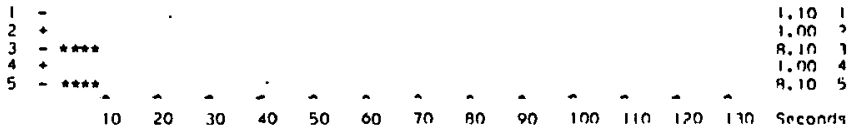

Test Trials

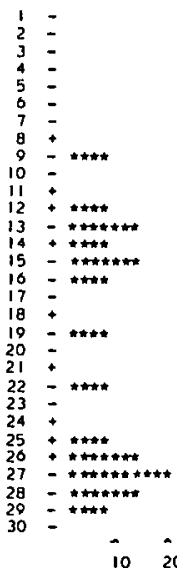

m

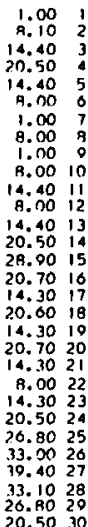

20.5030

TEST TRIALS NEAN $S D$ GREATEST

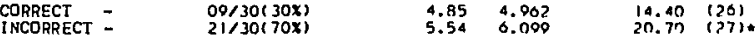

Figure 8 - Nonsense Syllable Trigram Discrimination Performance for Patient \#52.
Figure 9 and 10 show his performance. On ABAl he performed at a $43 \%$ level of accuracy. His maximum delayed interval was 39.60 seconds. On ABA2 his accuracy was $40 \%$ with delayed interval ceiling of 14.50 seconds. These findings are compatible with a severe memory disorder.

\section{DISCUSSION}

Memory deficits are the logical focal point for the analysis of behavioral disorders in the dementias. The present study demonstrates the application of the adjusting delayed matching to sample (DMTS) procedure in the analysis of memory disorders in the neurologically impaired aged. The results presented demonstrate the sensitivity of the computerized memory assessment titration procedure to neurological disorders. In addition to its diagnostic function, this procedure can be used to precisely monitor the progression of the neurological disorder and its impact on behavior. The recent development of computerized axial tomography scanning provides the unique opportunity to precisely quantify and visualize non-invasively and in vivo structural changes in the individual brain (Roberts et al., 1976). The experimental analysis of behavior methodology can provide the precision required for the study of molar and molecular behavioral changes associated with structural changes in the brain.

Parsons (1970) has emphasized the importance and utility of the intensive behavioral analysis of a single subject in neuropsychology. He states that given quantitative techniques and meaningful methods of study, the single case should reappear in the literature. Skinner (1969) proposes that an analysis which recognizes the individuality of the person is particularly valuable when contact is made with other disciplines such as neurology, where idiosyncratic sets of variables must also be considered. The present study emphasizes the technical basis of psychology and proposes that the extent to which individual behavioral phenomena can be studied at any time is limited by the current state of behavioral technology. An increased awareness of the extent to which cur- 
NEUROPSYCHOLOOY LABORATORY - BAYLOR COLLEGE DF MEDICINE

[23\} TESTI 1ABAI DATEI ?Q-SEP-76 RIGHTHANDED MALE 49 YRS
DIAGNOSISI MID

DELAY INTERVAL

Practice Trials

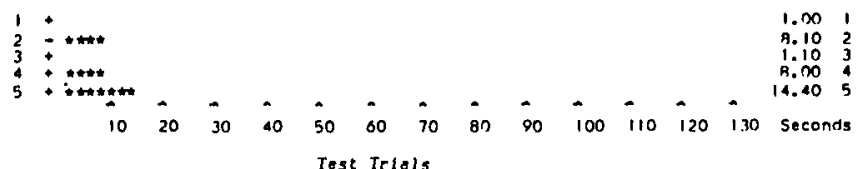

1
2
3
4
5
8
7
8
9
10
11
12
13
14
15
10
17
18
19
20
21
22
23
24
25
20
27
28
29
30

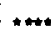

$=\ldots+\cdots$

$7=$

:

1

3

=

10

20

$22+\ldots+\infty$

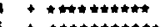

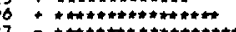

(t)

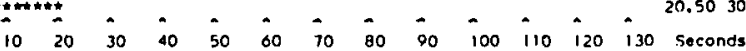

TEST TRIALS MEAN 50 GREATEST

$\begin{array}{llllll}\text { CORRECT }-: & 13 / 30(438) & 10.24 & 10.732 & 33.30 & (20) \\ 17 / 30(57 x) & 11.87 & 11.008 & 39.60 & (27)\end{array}$

Figure $9-$ Random Shape Discrimination Performance for Patient \#23.

rent practices are technically determined allows us to appreciate the implications of new developments more readily than would otherwise be possible. This is particularly important in the area of dementia, since the behavior of the aged individual deserves precise and rigorous measurement. The application of the system as a screening device in the assessment of mental changes in the elderly appears to be promising.

\section{REFERENCES}

D'AMATO, M. R. Delayed Matching and Short-Term Memory in Monkeys. In G.H. Bower (Ed.), The Psychology of Learning and Motivation. Academic Press, New York, 1973.

HONIG, W. K. Operant Behavior. Areas of Research and Application. Appleton Century Crofts, New York, 1966.

INGLIS, J. Memory Disorders. In C.G. Costello (Ed.), Symptoms of Psychopathology: A Handbook. John Wiley, New York, 1970.
KARP, H. Dementias in Adults, In A.B. Baker and L.H. Baker (Eds.), Clinical Neurology, Volume 2, Chapter 27. Harper \& Row, Maryland, 1976.

KIMURA, D. Right Temporal Lobe Damage: Perception of Unfamiliar Stimuli After Damage. Archives of Neurology, 1963. 8: 264-271.

MILLER, E. On the Nature of the Memory Disorder in Pre-Senile Dementia. Neuropsychologia, 1971. 9:7 75-81.

MILLER, E. Efficiency of Coding and the Short-Term Memory Defect in Pre-Senile Dementia. Neuropsychologia, 1972. 10: 133-136.

PARSONS, O. A. Clinical Neuropsychology. In C.D. Spielberger (Ed.), Current Topics in Clinical and Community Psychology. Academic Press, New York, 1970.

PEARCE, J. M. S. and MILLER E. Clinical Aspects of Dementia. Balliere Tindall, London, 1973.

PEREZ, F. I., GAY, J. R. A., TAYLOR, R. L., and RIVERA, V. M. Patterns of Memory Performance in the Neurologically Impaired Aged. The Canadian Journal of Neurological Sciences, 1975. 2: 347-355.
ROBERTS, M. A., CAIRCE, F. I., GROSSART, K. W. and STEVEN, J. C. Computerized Tomography in the Diagnosis of Cerebral Atrophy. Journal of Neurology, Neurosurgery and Psychiatry, 1976. 39: 909-915.

SHIMP, C. P. and MOFFITT, M. Short-Term Memory in the Pigeon: Stimulus Response Association. Journal of the Experimental Analysis of Behavior, 1974. 22: 507-512.

SIDMAN, M., STODDARD, L. T., MOHR, J. P. and LEICESTER, J. Behavioral Studies of Aphasia: Methods of Investigation and Analysis. Neuropsychologia, 1971. 9: 119140.

SKINNER, B. F. Contingencies of Reinforcement - A Theoretical Analysis. Meredith Corporation, New York, 1969.

VANDERPLAS, J. M. and GARVIN, E. A. The Association Value of Random Shapes. Journal of Experimental Psychology, 1959. 57: 147-154.

WITMER, L. R. The Association Value of Three-Place Consonant Syllables. Journal of Genetic Psychology, 1935. 47: 337-359. 